\title{
All the Easy Jobs are Filled: The Enduring Promise of a Life in Medicine
}

Maurice A. Mufson, MD

ABSTRACT

The 2020 commencement speech for Marshall University Joan C. Edwards School of Medicine.

\section{KEYWORDS}

Graduation, Keynote Speech, Medical School Graduation, Medical School Class of 2020
Author affiliations are listed at the end of this article.

Correspondence to: Maurice A. Mufson, MD Marshall University Joan C. Edwards School of Medicine mufson@marshall.edu
Welcome. Thank you for the honor of addressing the class of 2020.

Today, the School of Medicine's graduation marks a unique and unwanted, but necessary, accommodation of the COVID-19 pandemic, which has engulfed and humbled us and our families, frontline health care providers, our community, state, country, and world. This online graduation ceremony is a first for me, too. Every virus pandemic of the 20th and 21st centuries caused many deaths and widespread havoc, but maybe none have been worse than COVID-19, which has ravaged innumerable people around the globe. Physicians and medical staff answered the call with heroic action and continue to do so.

During the 1957 flu epidemic, I was an intern at Bellevue Hospital in New York City when the new Asian Influenza virus carved its path of disease and death around the US. All house staff, nursing staff, and faculty received the influenza vaccine. The ward, a wide and long single room, held forty beds. Curtains on roller frames served as temporary privacy dividers. Soon, overwhelming numbers of New Yorkers fell ill. Many needed in-hospital care, and many died. Old-style ambulances transported about twenty people on each run. Handouts in English and Spanish describing influenza were distributed. The house staff worked long hours. By spring, the virus had run its course and we returned to our usual routines. Although that was a difficult time, our present COVID-19 pandemic, unfortunately, greatly surpasses it.

We will never forget COVID-19. Your graduation is an amazingly bright and deserved occasion in the middle of an unforgettable pandemic. You will always remember it. Today, you graduate as well-educated physicians, ready to complete your education as residents, and capable of representing your profession for a lifetime. COVID-19 has changed so much of our lives and how you expected to spend your graduation day, but it will not prevent the awarding of your diploma.

In 1976, I became the founding chair of the Marshall Department of Medicine. On my first day in the department, I was its only member, which I expected. No instruction book or roadmap existed for its formation and organization. I was an academic pioneer, and I felt that pioneering spirit as I and 
a small group of faculty launched the School of Medicine. I had never envisioned this career path. Each of you in the class of 2020 might be experiencing that pioneering spirit today, your first day as a physician. Today, on your graduation, it is impossible for you to know precisely where your career path will take you.

Most of the critical tasks proved easy for me to discern. As a new medical school, few departments enjoyed the leadership of a chair. I began the development of the structure the Department of Medicine required. The first person to join me in the Department of Medicine was Mrs. Joyce Ray, my secretary, who remained in the Department for many years. Along my way, many professionals and staff helped me achieve my goals. You will benefit from the same support. I recruited the initial faculty members for the Department, completed the application for an internal medicine residency, managed my research laboratory at the Huntington VA Hospital, and answered a few consults in Infectious Diseases. Within three years, I had recruited sixteen faculty members. Within five years, the faculty number increased to twenty-three generalists and specialists, most of whom held joint appointments at the VA Hospital. Some of those early faculty remained in the Department for decades; they might have been your teachers.

The next four decades marked an astounding maturation of the School of Medicine and its two community-affiliated hospitals, Cabell Huntington Hospital and St. Mary's Hospital. Today, the Department of Medicine represents the largest department in the School of Medicine, with approximately fifty faculty members, sixty-four residents, and nine fellows. Huntington is now home to the second-largest medical system in West Virginia, Mountain Health Network. Forty-five years ago, when the School of Medicine recruited me and other department chairs, no one envisioned that it would change the medical education and health care not only in Huntington but also in most of this Appalachian area. I became an Emeritus Professor in 2002 , and I am the only original chair active in the School of Medicine today.

Four or five years ago, you received notice of your most recent life-changing event in a letter from the Marshall University School of Medicine, welcoming you to the class of 2020. I can sense the joy that each of you voiced and shared with your families, no different than the joy I felt when I received my medical school acceptance letter many decades ago. Today, I posit that graduation from the School of Medicine ranks as an equally important milestone in your medical career as receiving your acceptance letter from your residency. You join a great group of 1,905 School of Medicine alumni.

Now, you can almost see the "horizon" at the completion of your residency or fellowship that marks the start of your life-long career as a physician. I wish for each of you the great joy and unique satisfaction that only a career in medicine can provide.

Primary care physicians establish in-depth relationships with their patients, which builds satisfaction for both the patients and the physician. Once, when I was a second-year resident in the late 1950s, my Uncle Sam, a physician, called to ask me to cover his general practice because he needed elective in-hospital care for about two weeks. He gave me a list of his patients, loaned his doctor's bag and car to me, and explained that I could keep all the fees. He told me what he charged and recommended that I charge the same. I held office hours in his office and made house calls in the neighborhood of his medical practice in New York City. He alerted all of the patients and their families that his nephew would treat them in his medical office at their regular appointment times and make house calls. My fees were the same as my uncle's: three dollars for an office visit and five dollars for a house call. Each patient paid in cash. Credit cards and health insurance were the future. It was an honor to cover his practice for him.

I loved the experience. It represented my first opportunity before the completion of my residency for "real patient care." I quickly recognized that patient care held many memorable moments and that a lifetime of one-on-one patient care would be greatly rewarding.

Almost all of you will or have decided on clinical mds.marshall.edu/mjm

(c) 2021 Marshall Journal of Medicine
Marshall Journal of Medicine Volume 6 Issue 3 
practice as your career path. The patient-physician relationship remains unique to the profession of medicine and distinguishes it from all other professions. The medical care of the patient, and the preservation of their dignity, autonomy, and safety when they are ill and thus vulnerable, must be placed above all else by the physician, especially above self. Trust in the patient by the physician and the trust of the physician by the patient underlies the patient-physician relationship. It forms the bond that comforts patients through the worst of times: ill health, the death of a spouse or child, and chronic life-threatening or life-ending disease. As physicians, we preserve this bond. We communicate and heal within the limits of modern medical care. Sometimes we achieve success and sometimes not, but at all times we must trust each other. Every time I met with a patient for their medical care, whether in the clinic or the hospital, I felt humbled by the responsibility of caring for them. I sensed that they expected that I would act in an ethical manner in treating them, as I expected it of myself. Clearly, medicine's endearing motto must be "the patient above all else."

Patients want to place their trust in you. They will tell you their most intimate thoughts and reveal to you their most private feelings and actions because you are their physician and they need you to listen, to understand, to care for them, and to offer them comfort. In good times and in bad, they trust you and confide in you. Your relationship with your patients remains grounded in trust for all your practice days. Never disappoint any patient and never break your bond of trust with them.

All practice days are not perfect. As your practice of medicine matures, many days will be "shout-fromthe-roof-tops great" and you will cherish them for a lifetime.

Your patients will love those days, too; however, some days will not hold any thrills and other days will be "downers." Then, you will need someone with whom you can share your stress, who will keep secret your feelings and raise up your spirits. That confidant will likely be a trusted relative or friend, or your medical practice colleague. All physicians eventually manage these times and you will learn from these experiences.
The "boots-on-the-ground" patient care practice of medicine and the academic practice of patient care, teaching, and research, offer two distinctive career choices. Yet, both promise sufficient opportunities to satisfy the inquisitive and dedicated physician, and, at times, they can be combined.

Every patient is a one-person research project from whom you collect evidence, including history and physical examination findings and laboratory tests and radiographic procedures. You will analyze the evidence to arrive at a correct diagnosis and initiate treatment. Similarly, this approach is the basis for research on large groups. After I completed my first two years of an internal medicine residency, I enlisted in the U.S. Naval Medical Corps to satisfy my obligation for then compulsory military training as I received deferments for college and medical school. Fortunately, I was assigned to the Marine Corps Recruit Depot in Parris Island, SC, where atypical pneumonia was endemic. At first glance, this billet did not seem a winner, but serendipity was on my side because that endemic pneumonia turned out to be Mycoplasma pneumoniae pneumonia and I was a member of the Navy/NIH team that made the discovery. ${ }^{1,2}$ Afterwards, I conducted research for four years on respiratory viruses at the National Institute of Allergy and Infectious Diseases, which is now at the forefront of the COVID-19 crisis., ${ }^{3,4}$ At that moment I was headed for academic medicine, which became my lifelong career. Each of you will benefit from your serendipitous moments during your career in medicine.

For those who choose an academic career path, it begins post-residency by securing a position in the laboratory of a savvy research mentor. Your goal is to choose a research area you find exciting, conduct creditable research with your mentor, and publish several articles in quality journals. Count on your several publications and a recommendation from your mentor to land your first academic appointment.

When I was recruiting faculty for the new Department of Medicine at Marshall, I often quoted to a faculty candidate an aphorism of mine (you might call it a "Mufsonism"), namely, "all the easy jobs are filled." Nonetheless, when you near completion of your residency or fellowship and concentrate on your 
search for a career position, choose one for which you have the most passion because it will motivate you every day and encourage you to excel.

Now, for the inside information about so-called "easy jobs." There are no easy jobs in medicine. When you accepted a place in the Marshall Medical School class of 2020, you committed to the responsibility for the care of patients, for their health and safety, and for the responsibility to educate the physicians of tomorrow. Whether you choose a career as a clinical practitioner, as most graduates do, in primary care or another specialty, or choose academic medicine, the responsibility you assume in the care of patients will be a challenging job.

My bottom line is, and I hope yours is the same, that I would not trade my career in medicine for any other profession.

The profession of medicine has changed much since I graduated from medical school over six decades ago, and it has changed at a more rapid pace since you began your first year in medical school. Some changes will simplify your daily experiences and some changes will add complexity. Advances in artificial intelligence will drive many changes in the development of medicines and patient treatment. New medicines, vaccines, and monoclonal antibodies will enable you to treat diseases that are untreatable now, and this pandemic illustrates the difficulty in doing this. These challenges will be your opportunities.

Remember, your patients need you. You represent an important tower of strength in their life. Insist that your patients become vaccinated. Please do not neglect your own health and well-being. Take time for frequent deep breaths, spend quality time with your loved ones, exercise often, read a good book now and then, and watch many sunsets.

Medicine is the noblest profession. I welcome you to the profession of medicine, to a lifetime of responsibility, excitement, and great success.

\section{AUTHOR AFFILIATIONS}

1. Marshall University Joan C. Edwards School of Medicine, Huntington, West Virginia

\section{REFERENCES}

1. Mufson MA, Manko MA, Kingston JR, Chanock RM. Eaton agent pneumonia-clinical features. JAMA. 1961; 28;178:369-74.

2. Mufson MA, Sanders V, Wood SC, Chanock RM. Primary atypical pneumonia due to Mycoplasma pneumoniae (Eaton Agent): Report of a case with a residual pleural abnormality. $N$ Engl J Med. 1963;16;2681:1009-1111.

3. Mufson MA, Chang V, Gill V, Wood SC, Romansky MJ, Chanock RM. The role of viruses mycoplasmas and bacteria in acute pneumonia in civilian adults. Am J Epidemiol. 1967;88(3);1526-44.

4. Mufson MA, Kawana R, James HD Jr, Gauld LW, Bloom HH, Chanock RM. A description of six new rhinoviruses of human origin. Am J Epidemiol. 1965;81:32-43. 